\title{
Exergetic Optimization of Power Generation Systems
}

\author{
Pouria Ahmadi, ${ }^{1}$ Halil S. Hamut, ${ }^{2}$ Ahmadreza Ghaffarizadeh, ${ }^{3}$ \\ Pedram Hanafizadeh, ${ }^{4}$ and Esmaiil Ghasemisahebi ${ }^{5}$ \\ ${ }^{1}$ Fuel Cell Research Lab (FCReL), Simon Fraser University (SFU), Vancouver, BC, Canada \\ ${ }^{2}$ Technological Research Council of Turkey, Kocaeli, Turkey \\ ${ }^{3}$ University of Southern California, Los Angeles, CA, USA \\ ${ }^{4}$ University of Tehran, Tehran, Iran \\ ${ }^{5}$ Florida International University, Miami, FL, USA
}

Correspondence should be addressed to Pouria Ahmadi; pahmadi@sfu.ca

Received 19 May 2016; Accepted 19 May 2016

Copyright (c) 2016 Pouria Ahmadi et al. This is an open access article distributed under the Creative Commons Attribution License, which permits unrestricted use, distribution, and reproduction in any medium, provided the original work is properly cited.

With increasing global population and dwindling energy sources, generation of energy in a cost-effective manner with minimum waste and environmental footprint becomes one of the greatest challenges of our time. Thus, there is an increasing need for more capable and intelligent use of energy sources by incorporating enriched designs and optimized algorithms to enhance the sustainability of energy systems through innovative solutions. In this regard, the methods and tools for novel analyses and evaluation of energy systems to improve their efficiency and reduce their cost and environmental impact become imperative and require significant attention.

Recently, exergy has become a new distinct discipline for system design, analysis, optimization, and performance evaluation; and its use has been expanded drastically. Many researchers and practicing engineers refer to exergy methods as powerful tools for analyzing, assessing, designing, improving, and optimizing systems and processes. Exergy analysis appears to be an important tool to industry in (a) addressing the impact of energy resource utilization on the environment and economics, (b) furthering the goal of more efficient energy resource utilization, (c) determining locations, types, and true magnitudes of wastes and losses, (d) revealing whether or not and how much it is possible to design more efficient energy systems by reducing the inefficiencies, and (e) providing a sustainable development as a result of sustainable supply of energy resources. Exergy analysis is a method that uses the conservation of mass and conservation of energy principles together with the second law of thermodynamics for the analysis, design, and improvement of energy systems. The exergy method is a useful tool for furthering the goal of more efficient energy resource use, for it enables the locations, types, and true magnitudes of wastes and losses to be determined. Many engineers and scientists suggest that the thermodynamic performance of a process is best evaluated by performing an exergy analysis in addition to or in place of conventional energy analysis because exergy analysis appears to provide more insights and to be more useful in efficiency improvement efforts than energy analysis.

In the following, a brief overview and summary of the individual contributions are given.

The first contribution in this issue from S. Khanmohammadi et al. (University of Guilan, Rasht, Iran) is titled "Modeling and Assessment of a Biomass Gasification Integrated System for Multigeneration Purpose." This paper focuses on the accurate modeling of biomass gasification process and the optimal design of a multigeneration system (heating, cooling, electrical power, and hydrogen as energy carrier) to take the advantage of this clean energy. In the process of gasification modeling, a thermodynamic equilibrium model based on Gibbs energy minimization is used. The results show that with exergy efficiency as an objective function this parameter can increase from $19.6 \%$ in the base case to $21.89 \%$ in the optimized case. Also, for the total cost rate of the system as an objective function, it can decrease from $154.4 \$ / \mathrm{h}$ to 145.1 $\$ / h$. 
The paper by M. Khademi et al. (Islamic Azad University, South Tehran Branch, Tehran, Iran) is titled "Power Prediction and Technoeconomic Analysis of a Solar PV Power Plant by MLP-ABC and COMFAR III, considering Cloudy Weather Conditions." The authors try to predict the output power of a $3.2 \mathrm{~kW}$ PV power plant using the MLP-ABC (multilayer perceptron-artificial bee colony) algorithm. Experimental data (ambient temperature, solar radiation, and relative humidity) were gathered at five-minute intervals from Tehran University's PV Power Plant from September 22, 2012, to January 14, 2013. A detailed economic analysis is also presented for sunny and cloudy weather conditions using COMFAR III software. A detailed cost analysis indicated that the total investment payback period would be 3.83 years in sunny periods and 4.08 years in cloudy periods. The results showed that the solar PV power plant is feasible from an economic point of view in both cloudy and sunny weather conditions.

The paper "Exact Optimum Design of Segmented Thermoelectric Generators” by M. Zare et al. (Amirkabir University of Technology, Tehran, Iran) highlights the importance of thermoelectric generator for power generation. This study mainly focuses on the employment of exact method for design and optimization of STEGs and comparison of exact and approximate results. Thus, using new, highly efficient thermoelectric materials, four STEGs are proposed to operate in the temperature range of 300 to 1300 Kelvins. Design and performance characteristics of the optimized generators, including maximum conversion efficiency and length of elements, are calculated through both exact and approximate methods. The comparison indicates that the approximate method can cause a difference up to $20 \%$ in the calculation of some design characteristics despite its appropriate results in efficiency calculation. The results also show that the maximum theoretical efficiency of $23.08 \%$ is achievable using the new proposed STEGs.

The paper by Y. Abbasi et al. (University of Isfahan, Isfahan) is entitled "Performance Assessment of a Hybrid Solar-Geothermal Air Conditioning System for Residential Application: Energy, Exergy, and Sustainability Analysis." This paper investigates the performance of a ground source heat pump that is coupled with a photovoltaic system to provide cooling and heating demands of a zero-energy residential building. Exergy and sustainability analyses have been conducted to evaluate the exergy destruction rate and SI of different compartments of the hybrid system. The results show that the exergetic efficiency of the solar-geothermal heat pump system does not exceed 10 percent, and most exergy destruction takes place in photovoltaic panel, condenser, and evaporator. Although SI of PV system remains constant during a year, SI of GSHP varies depending on cooling and heating mode. The results also show that utilization of this hybrid system can reduce $\mathrm{CO}_{2}$ emissions by almost 70 tons per year.

Exergy and exergoenvironmental analysis of a CCHP system based on a parallel flow double-effect absorption chiller is conducted by A. Mousafarash (Shahid Rajaee Teacher Training University, Tehran, Iran). A CCHP system is comprised of a gas turbine, a heat recovery steam generator, and a double-effect absorption chiller. Exergy and exergoeconomic analyses are conducted as a potential tool to assess the system.
The results show that exergy efficiency of the CCHP system is higher than the power generation system and the cogeneration system. In addition, the results indicate that when waste heat is utilized in the heat recovery steam generator, the greenhouse gasses are reduced when the fixed power output is generated. In addition, an increase in gas turbine inlet temperature increases the system exergy efficiency and decreases the total exergy destruction rate consequently.

The last paper of this special issue by A. Rajaei et al. (Power and Water University of Technology, Tehran, Iran) is titled "Exergy and Environmental Impact Assessment between Solar Powered Gas Turbine and Conventional Gas Turbine Power Plant." In this paper a comprehensive comparison between these two systems in terms of energy, exergy, and environmental impacts is carried out. To evaluate the effects of energy resources relevantly, exergy destruction rates are categorized into two types: renewable and nonrenewable which expresses how much green the cycles are. Nonrenewable exergy destruction and loss are reduced compared to GT with the recuperator cycle by $34.89 \%$ and $47.41 \%$, respectively. They defined a renewable factor to evaluate resources quality and measure how green an exergy loss or destruction or a system as a whole is. Reduction in $\mathrm{CO}_{2}, \mathrm{NO}_{x}$, and $\mathrm{CO}$ compared to GT with the recuperator cycle by $49.92 \%, 66.14 \%$, and $39.77 \%$, respectively, is in line with the renewable factor value of around 55.7 which proves the ability of the proposed green measure to evaluate and compare the cycles' performance.

This special issue tried to shed light on the importance of exergy analysis for better design, better efficiency, and better assessment of power generation systems. The exergy analysis has been extended to include environmental, economical, and societal considerations. Environmental issues such as air pollution, global warming, and recycling have been linked to exergy. In this regard, some methods such as "exergoecology" and "exergoenvironment" have been proposed. We are confident that there will be more advancements in this field which will be seen in the coming years. Although exergy analysis has helped to design more efficient energy systems, the connection between economy and environment is necessary as well.

\section{Acknowledgments}

We would like to express our sincere thanks to all the reviewers for the time they spent on the review process of this special issue.

Pouria Ahmadi

Halil S. Hamut

Ahmadreza Ghaffarizadeh Pedram Hanafizadeh

Esmaiil Ghasemisahebi 


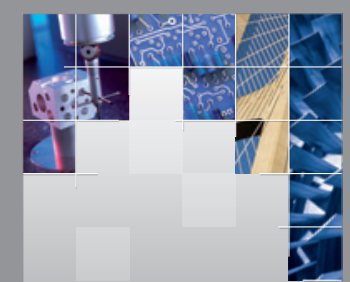

\section{Enfincering}
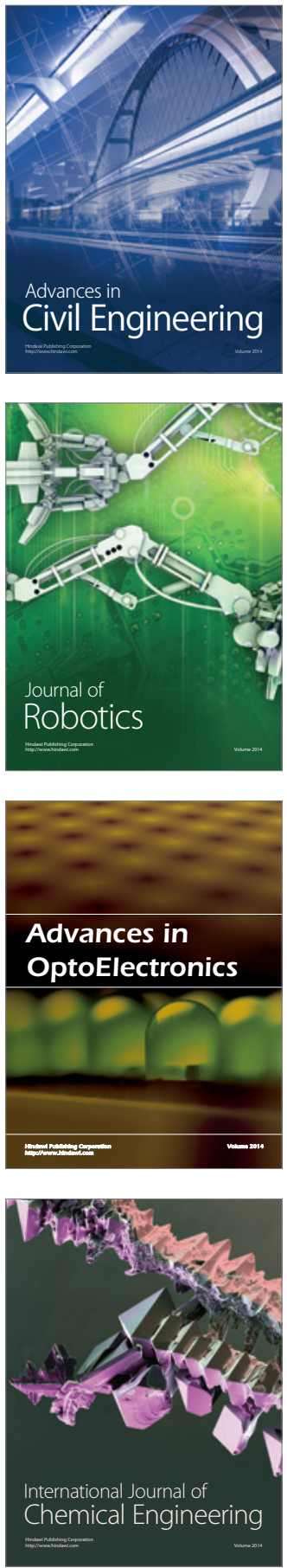

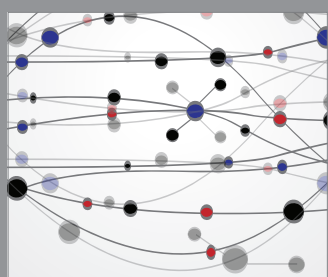

The Scientific World Journal

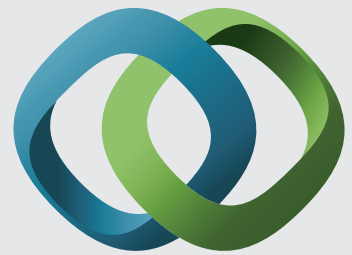

\section{Hindawi}

Submit your manuscripts at

http://www.hindawi.com
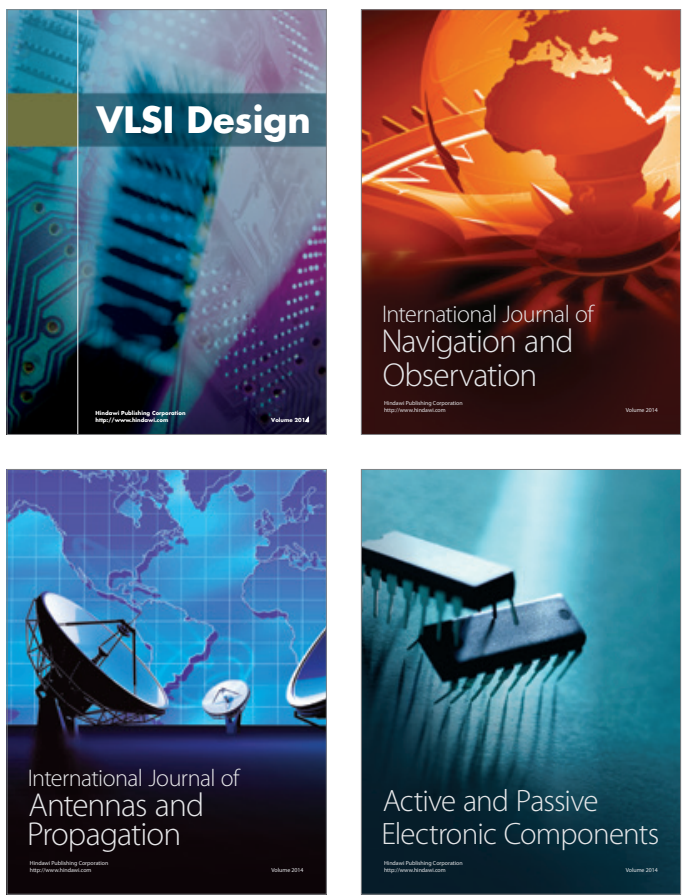
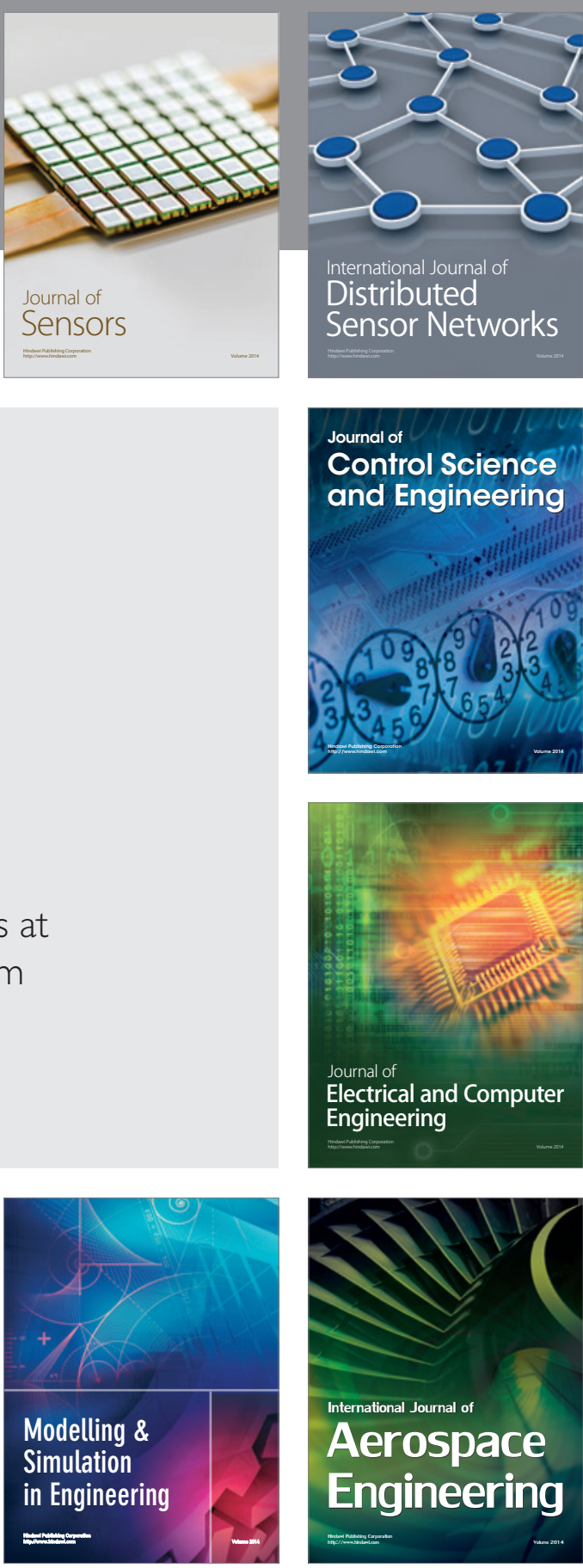

International Journal of

Distributed

Sensor Networks

Journal of

Control Science

and Engineering
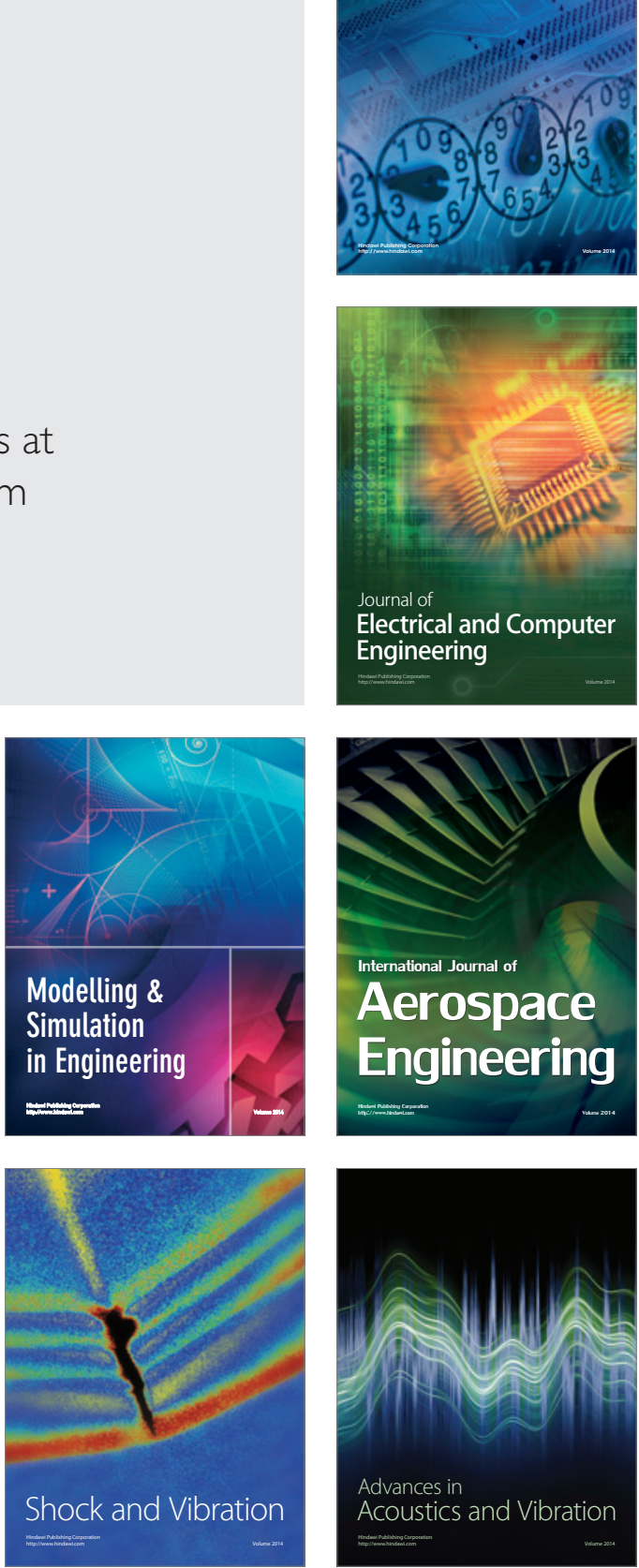